\title{
Efficiency of Stem Cell After Spinal Cord Injury with Clip-Compression
}

\author{
Tae Hoon Lee* \\ Department of Emergency Medical Service, Namseoul University, Korea \\ *Corresponding author: Tae Hoon Lee, Department of Beauty and Health, Namseoul University, Korea
}

Submission: September 27, 2018; Published: October 09, 2018

\begin{abstract}
Our experiment grafted mouse embryonic stem cell (mESC) to influence behavioral deficiency in rodent animal models of clip compressive surgery inducing spinal cord injury (SCI) of central nervous system. Our research proved the effect of grafted stem cells to the injured spinal cord region, focusing the application of mouse embryonic stem cells for regeneration of spinal cord nervous injury. Therefore, our research suggests manifest results that implantation of mouse embryonic stem cell could show behavioral improvement after severe spinal cord damage.
\end{abstract}

Keywords: Spinal cord injury; Implantation; Mouse embryonic stem cell

\section{Introduction}

It has been reported that administration of various stem cells applied into an injury-tissue area, resulting from a clip compression technique of the thoracic spinal cord region. These researches had suggested promotion of motor \& behavioral function in injured animal models, as tested by the Basso, Beattie, Bresnahan motor rating scale method [1]. Various trial of cell transplant has been showed to induce functional enhancement after severe spinal cord damage. Several studies evaluate lesser the progress of additional damage, minimizing the injured-inhibitory circumstance of the infarction region, changing damaged tissue with transplanted cells, rebuilding Schwann cells and axonal regeneration, and stimulating specific growth factor and intrinsic progenitor cells [2].

\section{Related Works}

Previous researches in rodent models occurring spinal cord damage have revealed that stem cell transplants survived well in the damaged spinal cord region, filled the cavitation region and found several neuronal cell types. Other studies showed that cell transplant improves motor functional recovery and induces the plasticity of related motor neurons.

\section{Proposed Method}

The clip compressive surgery used to induce spinal cord injury was a specific vascular aneurysm surgery clip, which has constantly been applied to induce neurologically spinal cord damage in animal models [3]. The specific spinal cord site was completely pressed for 60 sec dorsoventrally.

\section{Experimental Results}

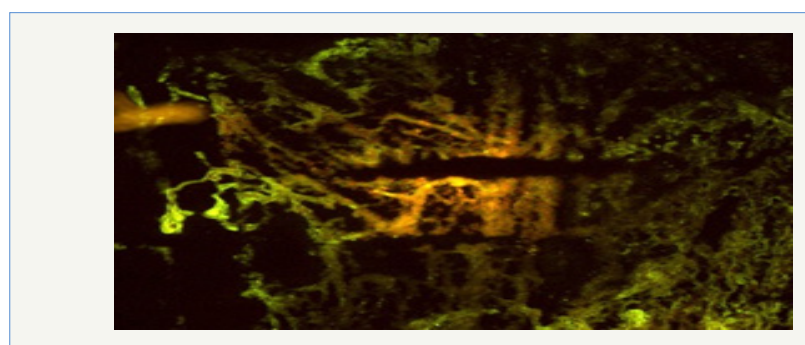

Figure 1: Transplanted cells show in fluorescent dye (yellow color) to the injured region of middle cerebral artery by GFAP (green).

Grafted cells survived to fill the injured cavity after transplantation of mESC. The spinal cord was stained for GFAP (green). mESC (yellow) labeled with a fluorescent dye migrated from their injection site to injured areas. Immunohistochemistry showed intensive glial reaction by GFAP-stained cells in the injured spinal cords (Figure 1). The transplanted mESC migrated into the injured sites and integrated into the scar areas. It is suggested that infiltrated mESC may produce trophic factors in order to reduce the cavities and improve behavioral function. However, transplanted mESC did not express GFAP, an astroglial marker.

\section{Conclusion}

Our research has demonstrated that the result of intra-cellular implantation in the damaged animal spinal cord site is proved to an effective \& significant enhancement in the BBB scale scores. 
Functional locomotive movement of the implanted group animals could be proved by a greater survival of regenerative axonal formation in the injured site. Previous studies strongly suggested that implanted cell survival resulted by significant reduction of neuronal cavitation tissue may facilitate motor and functional recovery [3]. mESC-transplantation group for at least five weeks post-transplant showed partially filling the cavities and connecting into the intrinsic spinal cord and resulted in reduction of a large amount cavity formation. It has been reported that reduction of cavity formation after spinal cord injury has been also experimented by implantation of various stem cells including marrow stromal cells $[4,5]$ and neural progenitor cells (NPCs) $[6,7]$.

\section{References}

1. Joshi M, Fehlings MG (2002) Development and characterization of a novel, graded model of clip compressive spinal cord injury in the mouse: Part 1. Clip design, behavioral outcomes, and histopathology. J Neurotra 19(2): 175-190.
2. Myckatyn TM, Mackinnon SE, McDonald JW (2004) Stem cell transplantation and other novel techniques for promoting recovery from spinal cord injury. Trans Immunol 12(3-4): 343-358.

3. Setoguchi T, Nakashima K, Takizawa T, Yanagisawa M, Ochiai W, et al. (2004) Treatment of spinal cord injury by transplantation of fetal neural precursor cells engineered to express BMP inhibitor. Exp Neurol 189(1): 33-44.

4. Houle JD, Tessler A (2003) Repair of chronic spinal cord injury. Exp Neurol 182(2): 247-260.

5. Euler MV, Seiger A, Sundstrom E (1997) Clip compression injury in the spinal cord: A correlative study of neurological and morphological alterations. Exp Neurol 145 (2 Pt 1): 502-510.

6. Basso DM, Murray M, Goldberger ME (1994) Differential recovery of bipedal and overground locomotion following complete spinal cord hemisection in cats. Res Neurol Neurosci 7(2): 95-110.

7. Ankeny DP, Mctigue MB, Jakeman LB (2004) Bone marrow transplants provide tissue projection and directional guidance for axons after contusive spinal cord injury in rat. Exp Neurol 190(1): 17-31.
Creative Commons Attribution 4.0 International License

For possible submissions Click Here

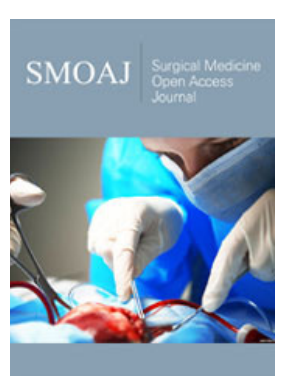

\section{Surgical Medicine Open Access Journal}

\section{Benefits of Publishing with us}

- High-level peer review and editorial services

- Freely accessible online immediately upon publication

- Authors retain the copyright to their work

- Licensing it under a Creative Commons license

- Visibility through different online platforms 